\title{
Posibilidades dialógicas de la visualidad poética en Calamina de Gladys González y Puentes de Alicia Genovese* $^{*}$
}

\author{
Fernanda Moraga García**
}

\begin{abstract}
Resumen
El objetivo principal de este artículo es explorar las interrelaciones poéticas entre imagen, lugar e intimidad como políticas dialógicas en el libro Calamina de la poeta chilena Gladys González (1981) y en el poemario Puentes, de la poeta argentina Alicia Genovese (1953). Aunque se trata de propuestas diferenciadas en sus distintos niveles de factura, pensamos que existe una zona fronteriza entre ambas que permite reflexionar en torno a las posibilidades de lo visual en la construcción de la imagen poética y también sobre el lugar de la enunciación como política dialógica. La relación entre imagen poética y lugar de enunciación se realiza a partir de las nociones de dilogía, alteridad e imagen poética. El artículo sostiene que el desenvolvimiento de una poética más visual en ambos poemarios, obedece al doble imaginario simbólico que tiene la articulación entre mirada y poesía. Esto favorece un "efecto visual" de la escritura que traspasa las fronteras entre la imagen, el lugar y la intimidad de las enunciaciones poéticas, provocando la desestabilización de patrimonios espaciales.
\end{abstract}

Palabras clave: poesía, imagen, intimidad, lugar, dialogía.

\section{Dialogical possibilities of the poetic visuality in Calamina of Gladys González and Puentes of Alicia Genovese}

\begin{abstract}
The main purpose of this article is to explore the poetic interrelations between image, place and intimacy as dialogic policies in the books Calamina by the Chilean poet Gladys González (1981) and in the poetry book Puentes of de argentine poet Alicia Genovese (1953). Although these are differentiated proposals in their different levels of form, we think that there is a border area between both that allows us to make a reflection on the possibilities of the visual in the construction of the poetic image and also on the place of enunciation as a politic of dialogic. The relationship between poetic image and place of enunciation is made from the notions of dilogy, alterity and poetic image. The article argues that the development of a more visual poetics in both poems, is due to the symbolic double imaginary that the look and poetry. This makes possible a "visual effect" of the writing that crosses the
\end{abstract}

Este trabajo es parte del proyecto Fondecyt 11150141, del cual la autora es Investigadora Responsable.

** Chilena. Doctora en Literatura Chilena e Hispanoamericana. Académica-Investigadora Universidad Andrés Bello, Santiago de Chile, Chile.moraga.fer@gmail.com 
borders between the image, the place and the intimacy of the poetic enunciations, causing the destabilization of space patrimonies.

Keywords: Poetry, Image, Intimacy, Place, Dialogic.

\section{Notas introductorias}

El objetivo principal de este trabajo es realizar un ejercicio de aproximaciones entre el poemario Calamina (2014) de la poeta chilena Gladys González y el libro Puentes (200o) de la poeta argentina Alicia Genovese. Este paralelismo permitiría, a pesar de que los textos se configuran como dos propuestas distintas en su factura poética, reflexionar en torno a tres aspectos que mantienen filiaciones. El primero de ellos es el aporte visual que entrega la imagen poética de ambos poemarios y, por otro, la importancia de la mirada como lugar de enunciación. Ambos elementos se vinculan con espacios mínimos - materiales y subjetivos- de la experiencia de las sujetos dentro de espacios urbanos marginales, de bordes o de tránsitos. Un segundo aspecto se relaciona con la escritura - poética- como un hacer de sobrevivencia para las sujetos de los poemas. Finalmente, una tercera filiación entre los textos y que atraviesa todas las anteriores es el complejo lugar de fronteras dialógicas, las cuales corresponden a márgenes de transferencias en/del territorio de la intimidad, las que no solo asignan un locus inestable de enunciación, sino también abren una relación de alteridad.

Para comenzar, parece pertinente una breve contextualización de los poemarios. El libro Calamina de González se inserta dentro de un escenario poético que comienza a hacer su aparición a inicios de 2000. Mientras las poéticas de los noventa representaban una estética de la soledad marcada por la reciente violencia de la dictadura y por el desencanto de la promesa de una democracia, los y las poetas del 2000 intentaban desasirse de los grandes relatos apostando por una poesía que pactaba con la tragedia de historias y espacios de lo íntimo. Esta promoción de poetas se caracteriza por recuperar espacios urbanos marginales - proyecto emprendido por la poesía de los ochenta y continuado en los noventa-, ligados a voces poéticas migrantes que dan cuanta "de una ciudad poscatástrofe, deteriorada, donde no hay opción de diseñar un proyecto personal y solo vale aprender a morir" 
(Sepúlveda 256). Por su parte, la primera edición de Puentes de Genovese, obra publicada en 2000 por Libros de Tierra Firme, se construye como un diálogo intertextual entre poesía y fotografía, contribuyendo a la diversificación artística que se venía dando en los noventa en el campo de la poesía argentina. La poética de esos años se proponía abandonar el apego a los sistemas estéticos que dominaban la escena de la década anterior - el neobarroco, el neorromanticismo y el objetivismo-, para asumir un/a sujeto lírico/a más errante y una factura poética que interactúa con materiales provenientes de lo visual (el cine, la fotografía, series de la televisión, etc. $)^{1}$. De este modo, el doble registro estético del libro de Genovese hace ineludible una lectura de colaboración entre ambos soportes de la imagen poética ${ }^{2}$. Sin embargo, la versión con la que se trabaja en este estudio se encuentra en el texto compilatorio realizado por la misma poeta: La línea del desierto. Poesía reunida que publicó Ediciones Gog y Magog, en 2018 ${ }^{3}$. Esta edición del poemario no incluye las imágenes fotográficas, por lo que nuestra lectura se enfocará en la visualidad que entrega el soporte lingüístico de la enunciación poética.

Sin querer ser exhaustivos, al referirnos a la visualidad de la imagen poética no lo hacemos a partir de una relación entre texto e imagen en la cual el texto representa alguna imagen ausente (Mitchell 2009) o cuando, entre ambos, se establece alguna intertextualidad. Por el contrario, nos interesa esta relación por el espacio que las palabras elaboran y a través del cual se enfatiza una visualidad que no necesariamente tiene un asidero en otras iconografías artísticas. Con esto, se quiere decir que la imagen visual construida por el lenguaje poético empuja la lectura hacia la materialidad icónica que la misma imagen poética quiere significar o "describir". Por lo tanto, más que preocuparse por poemas "visuales", los textos de González y Genovese subrayan la visualidad de los poemas por medio de la cual el locus se transmuta en focus organizando la mirada de la enunciación poética (Puppo 15-24). Este enfoque enunciativo se refuerza por la aparición de un espacio fronterizo, es decir, por la existencia de un

La misma autora afirma en un ensayo sobre la poesía argentina de los noventa, que es un momento en que se "reconfigura el lenguaje poético. Hay una nueva territorialidad en los textos, se ponen en escena otros referentes que dejan explicitado el deseo de que las impurezas irrumpan en el terreno de la lírica" ("Marcas de graffiti en los suburbios..." 200).

Para un análisis del libro en este sentido, se sugiere revisar los valiosos trabajos realizados por Alicia Salomone (2009) y América Salinas (2014).

3 Se trata de una compilación que reúne la poesía publicada de la poeta y, además, incluye un libro inédito que le da nombre al volumen. 
lugar de tránsitos que justamente se da entre la visualidad intencionada de la imagen poética y la misma escritura. Incluso, como veremos más adelante, esto se ve acentuado por la necesidad vital del oficio del hacer poesía en ambas sujetos poéticas. En esta interrelación que produce la imagen poética, el ojo se encuentra en la palabra; así lo afirma Lyotard (1979), al decir "que no hay lenguaje articulado sin la exteriorización de un 'visible', en el seno del discurso, que es su expresión” (32). En esta perspectiva, la visualidad de la palabra se transforma en una trasferencia de alteridad, es decir, logra que lo "otro" del lenguaje comunique, se convierta en posibilidad de enunciación. El lenguaje, dice Lyotard, no es un sistema uniforme, no puede serlo porque como interlocutor tiene la doble función de dejar al descubierto lo sensible y de interiorizar lo figural en el medio articulado que es el lenguaje (32). Expresado de otra manera - y pensando en los poemarios que nos ocupan-, la escritura se desdobla ofreciendo al ojo una deriva visual de la palabra, lo que no es otra cosa que la aparición de una diferenciación, de una alteridad en el signo. Por su parte, Jacques Rancière (2011) también distingue que la relación texto e imagen es de alteridad entre un yo y un otro, porque "si ya solo hay imágenes, no hay un otro de la imagen. Y si ya no hay un otro de la imagen, el propio concepto de 'imagen' pierde su contenido, ya no hay imagen" (23). Por lo tanto, el contenido que existe en esta relación de visualidad y escritura es el reconocimiento de experiencias y, por lo mismo, se manifiesta como un lugar inestable de transferencias, donde lo visual y lo escritural se pactan, se traducen y también se expropian. (Alberdi 23).

A partir de esta breve reseña sobre la relación de alteridad que existe entre la mirada y la escritura, es que proponemos que ambos poemarios permiten una lectura migrante entre uno y otro enunciado para reflexionar en torno a las posibilidades de lo visual en la construcción de la imagen poética y también, sobre el lugar de la enunciación como política dialógica.

\section{La ciudad es un gran cascajo de vidas ${ }^{4}$}

La conocida pregunta de Georges Perec (2007), sobre cómo dar cuenta de lo habitual, cómo interrogar o describir "lo que ocurre cada día y vuelve

Tomado de la entrevista realizada a Gladys González en 2018. 
cada día, lo trivial, lo cotidiano, lo evidente, lo común, lo ordinario, lo infraordinario, el ruido de fondo" (23); pareciera estallar políticamente en el libro de Gladys González. En Calamina se identifican de forma manifiesta las rutinas de una realidad precarizada que existe en los cegados intermedios del orden neoliberal. Esta factura explícita de lo cotidiano funciona como respuesta estratégica, ya que abre posibilidades a la exposición de la miseria a través del enfoque de las imágenes las que, a su vez, tienden puentes afectivos entre las subjetividades que adoptan los espacios, los objetos y los cuerpos. Así, se trataría de una “poesía escópica" como afirma Lorena Amaro (2018) al referirse al libro Bitácora (2018) de Gladys González ${ }^{5}$ y que en el caso de Calamina, se desplegaría en el efecto viceversa que se da entre la experiencia de la hablante, la existencia de los objetos, de los lugares y de los sujetos que se miran. En este sentido, las imágenes poéticas de lo cotidiano que se desprenden de esta relación "escópica”, muchas veces se aproximan a una proyección de fotografías o funcionan próximas al movimiento de diapositivas o, como dice González, actúan "como un pequeño corto, bien visual y bien acotado" que permite interpretar - la historia- a partir de la imagen y no del texto (González en Urzúa s. p). El juego entre el tránsito y la fugaz fijación de las imágenes, corresponde a un movimiento que se enmarca dentro de la intimidad — política — de la mirada y con la cual la sujeto poética procura resistir a la constante amenaza de una precariedad total, aunque por momentos o, finalmente, no le sea posible. Es así que la hablante busca el afecto a través de leves movimientos en la construcción de alguna memoria y de algún lugar que amortigüe el desamparo de su trayecto y le ofrezca, aunque sea provisoriamente, cierto arraigo a su experiencia.

La historia del poemario transcurre en una bahía que, según la misma autora, "tiene que ver con Valparaíso", pero también "podría [suceder] en cualquier otro lugar” (González en Urzúa s. p.). Pensamos que dejar abierta la construcción de este espacio como posibilidad de ser otro, potencia la heterotopía y distopía del desplazamiento de la sujeto poética. De este modo, también se puede evitar la fijación de una marginalidad a modo de un reverso de la postal turística que revela un enclave patrimonial oficial y que trasciende como un exotismo "Valpo"

Otros poemarios de la autora son: Papelitos (2002), Gran Avenida (2005), Aire quemado (2009), la compilación Vidrio molido (2011), Hospicio (2011), Última noche (2012), la compilación Pequeñas cosas (2015) y Bitácora (2018). 
luminoso y colorido, donde la pobreza es naturalizada como excedente folclórico del mito porteño ${ }^{6}$.

El libro es un tejido de significados que asedia nuestra percepción cotidiana, no en el intento de dominar ciertas "totalidades" parciales de la realidad, sino porque propone un trayecto hacia los precarios "territorios de la intimidad" (Arfuch 2013). En este sentido, el poemario no se encamina a una experiencia "privada" de la sujeto de los poemas dentro de un contexto espacial y temporal "propios"; la apuesta sería hacía la dimensión política de lo dialógico. Con esto nos referimos a la doble concepción bajtiniana de que la literatura - la novela diría Bajtín $(1989)^{7}$ - operaría como un discurso insubordinado y desmitificador de la realidad, por consiguiente, se transformaría en un posible espacio para la existencia de alteridades. En la literatura - como producto artístico, ético y de conocimiento- residiría la relación entre yo y otros con el propósito de reconocer su presencia (Bajtín 1997).

A esto se suma el juego entre "yo y otro" en la configuración de la imagen poética que se mencionó antes, vale decir, la alteridad que el libro de González propone a partir de la elaboración de la misma visualidad poética. Dentro de esta mirada, el poemario promueve una interacción dialógica entre la imagen y el texto que también colinda con el sentido de la "frase-imagen" presentada por Rancière. El filósofo francés reconoce que en la articulación texto-imagen, existe un vínculo entre un yo y un otro que produce complejas zonas fronterizas capaces de intervenir la concepción misma de representación:

Las palabras describen lo que el ojo podría ver o expresan lo que no verá jamás, adrede aclaran u oscurecen una idea [...] la imagen no es exclusividad de lo visible. Existen cosas visibles que no conforman una imagen, hay imágenes que son solo palabras. Pero el régimen más común de la imagen es aquel

\footnotetext{
"Valpo" corresponde a la abreviatura de Valparaíso y es usada de manera informal escrita y oralmente.

Para el autor ruso la poesía, al no apelar a una réplica, no se hace dialógica, por lo que es incontestable a pesar de las contradicciones que el poeta pueda señalar en la palabra. El poeta habla acerca de lo ajeno, pero en su propio lenguaje, no interactúa con otros lenguajes, sólo lo haría en lo que él mismo llama los géneros líricos "bajos" como la sátira, la comedia y otros. Para Bajtín (1989), entonces, "[e]n los géneros poéticos, en sentido restringido, no se utiliza, desde el punto de vista artístico, la dialogización natural de la palabra: la palabra es autosuficiente y no presupone enunciados ajenos fuera de su marco. El estilo poético es aislado, de manera convencional, de toda interacción con la palabra ajena, y sin ningún miramiento hacia la palabra ajena." (102). Sin embargo, pensamos que el dialogismo bajtiniano es, sin duda, extrapolable al campo de la poesía debido a los múltiples sentidos de comunicación que en ella se manifiestan.
} 
que pone en escena una relación de lo decible con lo visible, una relación que juega al mismo tiempo con su analogía y con su diferencia. Esta relación no exige en lo absoluto que los dos términos estén materialmente presentes. Lo visible se deja disponer en tropos significativos, la palabra despliega una visibilidad que puede ser enceguecedora. (28-29)

De este modo, proponemos que Calamina - y también Puentes de Genovese - elabora, ya a partir de la visualidad de la imagen poética, una enunciación de políticas dialógicas que disuelven cualquier intento unitario o "privativo" de la intimidad. En el marco de estas perspectivas, nos parece que el libro de González respondería a una sugerente práctica fronteriza en la experiencia espacio-temporal de la sujeto. El pausado ritmo de encuadre en el movimiento de las distancias y de las aproximaciones a los espacios y tiempos marginales de la ciudadpuerto, emerge como un reconocimiento mutuo en relación con las identificaciones que existen entre sujeto, mirada, espacio y objetos. En otras palabras, tanto los lugares y las temporalidades como la subjetividad de la hablante son parte de la misma precariedad en la construcción de la intimidad.

Esta orientación dialógica de un cotidiano degradado en González, tiene su analogía en la materialidad simbólica que da nombre a su poemario y que representa una crítica a la ocupación capitalista de la ciudad: la calamina. Según lo indica el mismo poemario, la portada y la contraportada del libro de González corresponden a una sola fotografía tomada por la autora. Podría tratarse de un techo, una pared o un cerco hecho de calamina oxidada que se presenta como el primer y el último enfoque del texto. La calamina, como ya bien ha sido mencionado en otros estudios sobre el libro ${ }^{8}$, es un elemento metálico de mala calidad, es decir, frágil y permeable, su color va cambiando y oscureciéndose por la corrosión y la oxidación. Finalmente, es un material que se deteriora y corroe por el accionar del clima y el paso del tiempo. Esta primera imagen que presenta el texto, a lo menos tiene dos dimensiones latentes para su lectura y también para la comprensión de la composición visual, política, ética y afectiva de los encuadres que se presentan. Una de ellas es que la fotografía, al tener una "continuidad" de tapa a contratapa al abrir el 
poemario, nos hace imaginar la figura de un "techo" de calamina oxidada. En nuestra perspectiva esto es una pista significativa, porque la forma que así expone el libro configura la cubierta de una vivienda-espacio de emergencia. Este punto de partida - y de llegada-, conformado por la frase-imagen fronteriza que se arma entre el título del poemario y la fotografía, prepara para una posible lectura respecto de algo irreparable en la experiencia.

La segunda dimensión es que, luego, en la lectura del poemario, esta imagen inaugural se continúa en el epígrafe que González presenta como antesala de sus poemas y que corresponde a un fragmento de la poeta porteña Ximena Rivera: "es probable que lo irreparable / continuamente aplastado / salte delante de nosotros / con esta necesidad que tiene / de imprecarnos con dureza" (7) ${ }^{9}$. Todo el poemario es una forma implícita de compartir - dialogar con - estos versos de Rivera, enfatizando en la fragilidad que produce lo irremediable en la existencia, como por ejemplo, la imposibilidad de un arraigo de los afectos. Esto último abre las puertas a la precariedad de la experiencia: "habitaciones sin paredes / jardines sin vida / en medio de los pasillos / tragaluces impenetrables / de fonola" (24). Del mismo modo que el contenido existencial desesperanzado que se anida en esta dialógica entre epígrafe y poemas, la oxidación y el envejecimiento de la calamina sugiere, además de lo mencionado, el paso del tiempo como resto, como sedimento de la memoria.

El cruce entre el tiempo inmediato de la memoria y el espacio presente de la sujeto, es un aspecto significativo del lugar de enunciación, porque da paso a ciertas fronteras temporales y espaciales de intercambio. A partir de ellas, se percibe que la enunciación está situada en la ambigüedad de un punto de no regreso, vale decir, se mueve, pero no avanza. Dicho de otra forma, el libro se construye como un fallido intento de retorno, como "una temporada en la bahía / [que] se queda inmóvil en el recuerdo" (25). De esta manera, al introducirnos en la lectura del poemario notamos que la existencia de la sujeto se proyecta dentro de mínimos y deteriorados márgenes urbanos del puerto. Por lo mismo, consideramos que el doble potencial que tiene la portada del libro funciona como marco expresivo para leer Calamina, ya que luego en su trayecto poético se distinguen territorios de la intimidad marcados por una vulnerabilidad radical. Así, se señala la existencia de vidas-lugares precarizados como lo son la casa,

Las cursivas son del original. 
el puerto, la habitación y finalmente, el cuerpo de la sujeto. Es a partir de ellos que la enunciación (re)enfoca la mirada de los lugares, los objetos y la memoria:

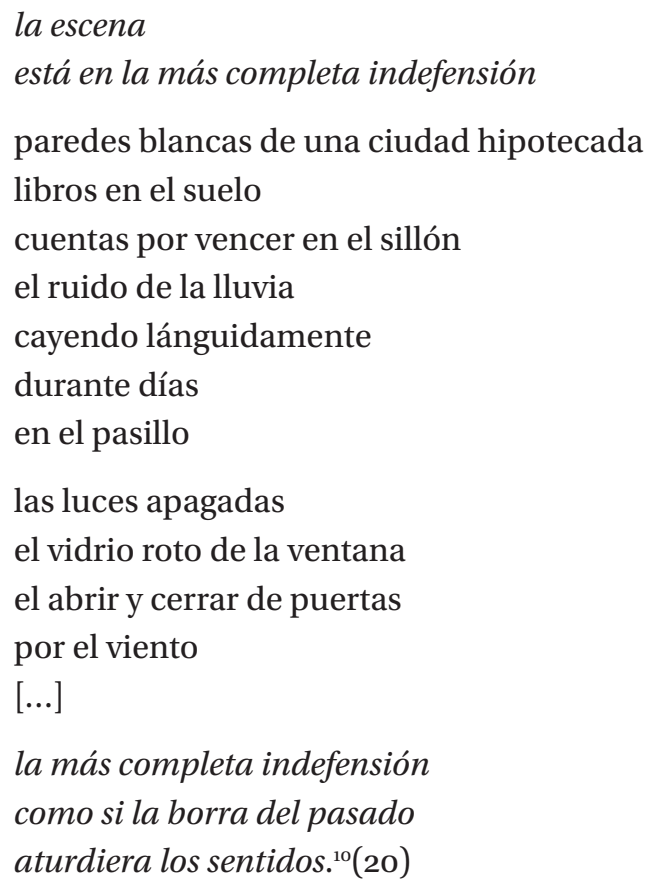

En estos fragmentos del poema significativamente llamado "Insomnio", el estado de vigilia introduce, como en un cuadro teatral, la reiteración de transferencias entre el desamparo de la sujeto y la precariedad de su espacio. Esta posición marginal que señala la enunciación no solo manifiesta su condición de residuo e invisibilidad, también la propone como una frontera social dialógica en cuanto asume un colectivo: "encadenando voces / y rostros/ como perros rabiosos / al solitario jardín del exilio" (20).

Al mismo tiempo que este contenido político se manifiesta como una cruda experiencia dentro de un puerto mercantilizado, también se revela una falta de amor, es decir, la urgencia por vínculos afectivos que sostengan esta vida vulnerada. Esta ausencia de afectos se transforma en el móvil de lo irreparable para la sujeto y en la visualización de este alrededor que, por momentos, es devastador en términos humanos. Junto

Las cursivas son nuestras. 
a esta privación vital en su existencia, se construye simbólicamente un lugar, la casa, la que con cierta parodia se pondera como imprescindible en la construcción de la soledad de la sujeto: "un nuevo camino / por el cual llegar / a lo que podrías llamar casa / grandes ilusiones / camufladas en el paisaje" (28) ${ }^{11}$. La casa sería el núcleo, algo mordaz, de la falta que acecha a la hablante y que la empuja a convertirse en una paria urbana: "de qué sirve este oficio / de marcar el paso en los terminales" (15). Se encuentra implícita aquí también la descomposición del sueño burgués de la "casa propia” y de una de sus ideologías más dominantes: la familia funcional al sistema. Este espacio familiar es problematizado a partir de su localización social dentro de los límites residuales de la ciudad, en los barrios pobres de la bahía, detrás del paisaje porteño:

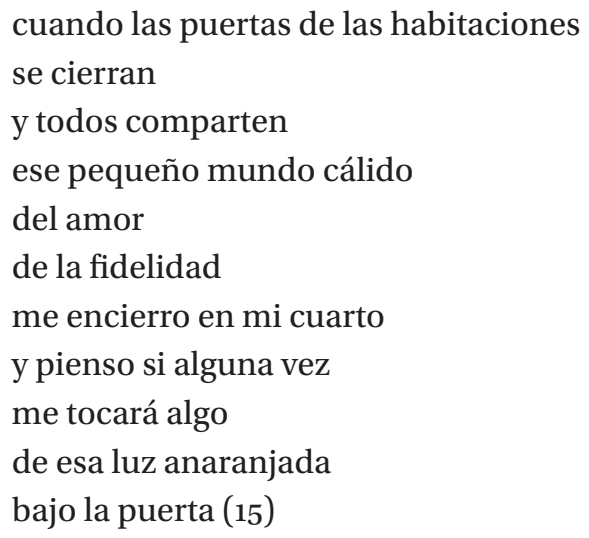

El espacio precarizado de la "casa" es recíproco a los objetos mínimos que lo pueblan, siendo estos tan fragmentarios y frágiles como la imagen de la casa. Ambos — casa y objetos - dan cuenta de un "estado de ánimo" material y subjetivo de la hablante: "el gastado papel mural" (14); "las luces apagadas / el vidrio roto de la ventana" (20); "tengo por escritorio / el esqueleto de una cama de madera/ duermo en un colchón viejo / sobre las tablas del piso" (17). De este modo, las cosas se transforman en energía visual latente en el espacio cotidiano de la sujeto. No se trata de la imagen de los objetos como tales, es decir, frágiles y despojados de cualquier fragmento que les pueda dar estabilidad o valor material; sino de la relevancia que tienen como mediadores entre la sujeto, el espacio y su experiencia. Está claro que los objetos pueden ser leídos como signos de interacción entre la experiencia temporal y espacial de

$11 \quad$ Las cursivas son del original. 
la voz enunciativa y vistos así, funcionan como figuras de resistencia al vaciamiento total de la subjetividad de la hablante. De esta manera, la casa y el hogar en Calamina, se construyen como una memoria-ilusión imposible de abrigo, de arraigo o de afecto. Por otra parte, también se constituye en una zona residual, de borde o de frontera como otras de las formas o posiciones del focus de enunciación.

Asimismo, postulamos que esta casa proyectada por González es sinécdoque de la ciudad-bahía. El libro comienza, en un primer nivel de lectura, con un lente detenido en la imagen de un puerto patrimonial que alimenta las postales para turistas: "los cerros / parecen un parque de diversiones [...] cenas con vino / conversaciones de sobremesa / y niños jugando a las escondidas / entre la escalera" (11). El poema se llama "Nocturno de bahía". Si pensamos en la gran tradición de los "nocturnos" en la poesía latinoamericana, especialmente de comienzos del siglo $\mathrm{XX}^{12}$, la noche se presenta como tema poético para ahondar en la intimidad de la existencia, más allá de lo meramente visible a la mirada exterior. Se produce una presencia expresiva, más que de la noche como tal, de la oscuridad existencial en que se encuentra el hablante lírico y desde la cual emerge el extrañamiento y el desacomodo del yo poético, es decir, es el momento en el que se desarraiga la experiencia de un mundo diurno, que no por decible o evidente, es más "real" o "verdadero" que el lugar de la existencia noctámbula. Más bien, el día correspondería al momento de hostilidad para el/la sujeto poético/a en cuanto representa una estructura de mundo visible que lo/la desanima. Por lo tanto, la imagen nocturna, en el sentido que hablamos, produciría una poesía que otorga una gran conciencia a la intimidad. Todo esto hace mucho sentido a nuestra propuesta, no solo para un segundo nivel de lectura del poema de González, sino también para ver-leer que Calamina se construye como un trayecto poético que se desliza por la oscuridad de una lúcida experiencia.

Respecto de lo primero, en relación con el poema "Nocturno de bahía”, parte de los fragmentos que se omitieron en la cita que hicimos quiebran la imagen que apela a una ciudad patrimonial tipificada en los cerros de colores y los restoranes populares-burgueses del puerto y

\footnotetext{
12 Imprescindibles son los “Nocturnos" del colombiano José Asunción Silva, del nicaragüense Rubén Darío, del mexicano Xavier Villaurrutia, del uruguayo Julio Herrera Reissig, del argentino Oliverio Girondo y, por supuesto, de la chilena Gabriela Mistral, entre otros más.
} 
por donde, seguramente, deambula el "feliz" flâneur benjaminiano. El poema se transforma en una simulación cuando hace entrar la opacidad de lo nocturno en su sentido poético: "los cerros / parecen un parque de diversiones / torcido / interminable / lejano" (11) ${ }^{13}$. Para luego, en el poema siguiente prevenirnos que: "los caminos de la bahía / llevan a pequeños espacios de dolor / que permanecen silenciosos" (12). Es más, la imagen que le continúa se desenvuelve como un lento movimiento fotográfico que va capturando sentidos directos de lo nocturno, en los cuales el afecto y el desamparo forman el vínculo político del enfoque que hace la sujeto poética:
un hombre
está tirado en el suelo
como un animal destripado
los pantalones abajo
sus genitales congelándose en la lluvia
un perro sostiene su cabeza
como si de ese hombre alcoholizado
dependiera su mundo (13)

Por último, esta poética nocturna de Gladys González también incluye las transiciones del día a la noche: "observo el atardecer / recostada sobre el techo". El atardecer es una frontera temporal y espacial para la hablante, entre el momento en que "el horizonte desaparece", "y las calaminas / secándose al sol / revelándose / en el silencio del óxido" (23). Esta posición fronteriza temporal y espacial de la enunciación trae, desde fuera y a modo de un espejeo con su propia intimidad, la precarización del puerto, en el cual se vislumbra "un paisaje / de metales quemados / enredaderas silvestres / hombres solitarios / hurgando en la basura / de casas demolidas" (23). La hablante se mimetiza con la imagen de la bahía convirtiéndose en el puente conectivo entre la cruda imagen de la pobreza y la fragilidad del momento que observa. Es una impresión devastadora, una atroz e íntima ruina que transita de manera recíproca entre los rincones diurnos y nocturnos de los poemas, señalando la labilidad de la existencia y la supresión del lazo amoroso. Pensamos que ambas serían el resultado de un sistema que funciona como máquina capitalista o, tomando prestadas las palabras de André Menard (2014), como una "maquinaria de producción de ruinas" (229).

13 Las cursivas son nuestras. 
Los diferentes sentidos en que se desplaza la experiencia $-\mathrm{y} / \mathrm{o}$ la mirada- de la voz que enuncia, además de escenificar el trayecto personal de la protagonista poética, representan de manera sintomática ciertos restos espaciales, temporales y humanos dentro de una ciudad atrapada en objeto de consumo turístico. Esta perspectiva, a veces próxima al horror, es la que se encuentra en el segundo plano de la "arqueología" poética de las imágenes que construye el texto. Un nivel que se encuentra por detrás, o más bien, formando parte de una zona fronteriza que insinúa un contexto demoledor. Dentro de la visualidad de los poemas, esta catástrofe funciona como un enmarque silencioso - pero no por eso ausente - de la mirada enunciativa. La mirada y la voz forman un tejido de umbrales dialógicos; esta voz que mira o esta mirada que enuncia, no pierde de vista aquellos mínimos recortes ruinosos e imperceptibles de un espacio y un tiempo bahiano por donde se desplaza, demorosa y solitaria, la sujeto de los poemas.

El movimiento visual ralentizado que genera el enfoque de la experiencia de la sujeto, contrarresta con la apabullante inmediatez del tiempo y de los lugares que se intuyen tras las imágenes: la velocidad neoliberal y tecnológica que produce cuerpos en/para el tributo material y virtual. Son las imágenes que no percibimos en el primer plano de los poemas, si no las leemos y las vemos a través de la intención de la autora de dar visibilidad al desamparo de la hablante, convirtiendo este segundo nivel en un trasfondo político de denuncia ética. De esta forma, por encima de este recuadro implícito - pero no invisibilizado- del relato, se halla manifiesta la historia de la protagonista. La hablante, situada en una marginalidad territorial, dentro y fuera a la vez del tiempo y el espacio de la ciudad neoliberal, se halla - a veces por voluntad y otras por imposición- en un exilio interior y exterior.

El destierro que a la hablante le provoca el viaje le proporciona memorias que esperan "olvidar el sabor amargo / de un invierno pobre, oscuro y frío / congelado como una postal / entre los recuerdos de una bahía" (30). Con este fragmento, hacia el final del libro, se cierra el poema llamado "Urgencias" y en el cual el relato aparece marcado por la voz suicida de la enunciación. La sujeto se encuentra en una sala de urgencias donde su cuerpo es el mayor referente visual de lo ruinoso: "un cuerpo mojado / envuelto en frazadas [...] el estado de turbación / de la mente por días /el desierto de un estómago / la flora intestinal / pudriendo las pastillas" (29). Es necesario mencionar que este poema, casi finalizando 
el libro, aglutina la relación hablante-lugar que cruza todo el poemario, es decir, el cuerpo de la sujeto suicida también es la representación de la degradación del espacio. El territorio del cuerpo dañado y autodañado consuma su precariedad reforzando el íntimo correlato que existe entre su experiencia y la descomposición del espacio, ambos como productos desechados por la mercantilización de la ciudad oficial. Finalmente, en esta relación de identificación, la memoria actúa como un puente a través de "los malos sueños" que dan paso a la imagen de "la orina estancada en las cañerías” (29). Este poema, como bien dice Eugenia Brito (2014), sería la imagen terminal con la que se cierra la casa poética de Calamina, la que, a nuestro juicio, se construyó desde la portada y contraportada del libro.

Los espacios y tránsitos de y por la marginalidad, como señalamos, trazan una resistencia al presente a través de la configuración de una política dialógica de la frontera que se construye entre la mirada, la voz, la memoria, los lugares, los objetos, la subjetividad y también la escritura. Esta es la construcción fronteriza de un adentro de la intimidad material y subjetiva, quedando a la vista una frontera de límite con otra realidad degradada: la tarjeta turística de un puerto.

En relación con la escritura, el oficio de la poesía como ejercicio vital de la sujeto en su sobrevivencia, es cardinal en las breves itinerancias de su enunciación. La imagen poética que entrega la mirada en los poemas no solo responde a la factura de un género literario - la poesía-, sino que la misma sujeto enfrenta sus solitarios tránsitos a través de su propio proceso escritural. En este sentido, Eugenia Brito afirma que los lugares desolados que aparecen en Calamina "establecen una poética dura, que aflige a la que escribe, pero que en su carácter inevitable se vuelve imprescindible como denuncia, como memoria y testimonio" (s/p). La escritura dentro de la escritura se convierte así en un vehículo de legitimación de la experiencia a través de la verbalización política que realiza la sujeto que escribe. La imputación a los efectos devastadores que la máquina capitalista produce sobre el espacio, el tiempo y la existencia humana se transforma en un discurso ético implícito del poemario. En consecuencia, se interrumpe la circulación de miradas oficiales, turísticas y patrimoniales sobre la destemplada lugaridad de la bahía, mostrando la violencia, el desecho y la degradación que produce el accionar de un sistema de mercado en todos los niveles de la experiencia, del cuerpo y los espacios. A esto se suma que la interacción entre enunciación y 
escritura, es decir, la articulación imagen-palabra posibilita a la que escribe, lo mismo que nos sugiere Alicia Genovese: “[...] una relación de cercanía o distancia con su objeto, proximidad o alejamiento que implica una posibilidad del yo [...], una ubicación del yo como quien ajusta una lente y le otorga a su objeto un foco, nítido, borroso, un primer o un segundo plano, una luz más tenue, más brillante o más sombría." (Leer poesía... 77).

De este modo, el libro de González lo entendemos como un empalme, como una superposición de discursos políticos directos, indirectos, fronterizos y también de recursos estéticos provenientes de estrategias visuales que fortalecen la factura sensorial de la palabra poética. De aquí que lo manifestado por Brito y Genovese tenga resonancia para nuestro trabajo, puesto que entre palabra e imagen poética no habría subordinación de una en la otra, sino una relación de transferencia simbólica que potencia lo visible, lo invisible y lo invisibilizado de un sistema y que, además, compromete la intimidad de la sujeto dentro de un marco de precariedad de su experiencia.

\section{Todo camino es un puente y todo puente es posibilidad de desvío}

En el libro Puentes de Genovese existen, a nuestro juicio, tres dimensiones poéticas imprescindibles: el puente, la memoria y la migrancia. Por cierto que en el poemario se hallan otras estrategias artísticas relevantes, pero por ahora destacamos estas, ya que en su articulación se desenvuelve una estrategia particularmente poética: la figura - metáfora- del desvío. El “desvío” (Ricoeur 2001) le confiere al discurso poético de la autora su materialidad afectiva y política de transgresión respecto de una organización establecida de la realidad y en cuya materialidad confluyen y se tensionan los sentidos del lenguaje y de la imagen poética. En esta dirección, la utilización de la figura del puente desde el título del poemario, se transforma en la "evidencia" de la función de movimiento que Genovese le otorga al espacio, al tiempo, a la palabra, a la imagen y, por supuesto, a la sujeto enunciativa. A esto se suma que el objetivo de esta movilidad es el cuestionamiento a los códigos que organizan la realidad simbólica. Así, la deriva que opera en la representación del puente y la memoria estaría directamente empalmada en el eje —creativo/político-del 
ejercicio poético de la misma hablante lírica. Con esto nos referimos al cómo la enunciación trae la realidad y la desvía hacia la intimidad de su experiencia espaciotemporal, produciendo el descentramiento de los signos espaciales y temporales de la historia de violencias recientes en Argentina y del diseño urbano moderno de la ciudad capital. Esta estrategia afecta directamente la construcción visual que maneja el poemario en cuanto altera la significación lógica de la figura del puente y su contexto. Por lo tanto, se produce una dislocación en la enunciación y en el enunciado (sujeto y puente) para construir una articulación coherente entre la sujeto y las memorias (imágenes) que quiere mostrar. Más que elaborar una nueva realidad, en los poemas se configura una diferenciación que puede señalar lo silenciado a través de la potenciación visual de la palabra poética.

A partir de lo dicho, comprendemos que la figura del puente en Genovese infringe las reglas de pertenencia fijadas al significado y establece un territorio distinto para darle accesibilidad al enunciado a través de las diversas figuras del puente que, a su vez, transportan variadas memorias de la enunciación. De esto se desprende, además, que la representación del puente en el poemario no existe solamente en el abandono de códigos prefijados, sino que su poetización se hace presente por medio de fecundas interpretaciones a la significación política y ética de la metáfora del puente en cuanto lugar de tránsito, experiencia, frontera, etc., y que, como dijimos, no solo es lingüística, sino que nutridamente visual.

De esta forma, el puente se construye para Genovese tal como se construye la experiencia temporal, es decir, soltando y enmarcando la memoria a un mismo tiempo, ya que así la sujeto de los poemas logra aprehender poéticamente el "objeto" - puente- en relación con su experiencia afectiva. A esto agregamos que los puentes físicos del poemario son reales: "Puente Avellaneda, Pueyrredón / Puente Alsina cambiando el nombre / en los mapas, por el mismo zanjón del Riachuelo / Puente la Noria. Pasajes /al otro lado de la ciudad (227). Se trataría de topos simbólicos en los cuales, sin embargo, "el tiempo se desata" (237) originando un lugar para el topos político, es decir, la hablante pone en juego su lugar de enunciación migrante. De este modo, el puente, la memoria y la nomadía parten de una inflexión de la palabra - de la imagen - con la que se tiende la posibilidad de desmontar cualquier plano oficial de la experiencia y la historia. 
Es así como el trayecto de la hablante lírica, marcado por su experiencia nómada, se inicia con una deriva: "me negué a coser/ a ser mi madre: / hierro apuntillado /en la orfebrería de Puente Alsina, / criar mujeres fuertes / y que todo pase por ellas/ [...]/ la hija huye para desear" (230). En esta cita, el último verso interrumpe la continuidad de un destino preparado como herencia de género y señala el comienzo de la itinerancia de la sujeto por diversas fronteras que, al mismo tiempo, son camino y desvío y que finalmente desembocan en el encuentro de la sujeto con la hija. De esta forma, la voz poética significa su propio reencuentro, introduciendo una alteridad: la hija huye de la madre y otra madre se reúne con otra hija. En esta interacción de las otras con/de sí mismas y en la cual aparece la interioridad como lugar de decisión y autoafirmación, habría que agregar que también interviene la alteridad del tiempo y el espacio: "un puente se hace/ en las historias / vueltas a contar/ En los cruces azarosos/ de personas y lugares / [...] / nudos en el cuerpo/ reactivos balbucean /[...]/ como agua crecida/ desde arroyos entubados/ que escapada vuelve a contar / a alterar el concreto" (Arfuch, "Cronotopías de la intimidad" 234). En este sentido, entonces, los poemas ofrecen una elaboración del espacio/tiempo no como una extensión homogénea sometida a una cronología de progreso, sino como una yuxtaposición de niveles, discontinuidades y disrupciones, zona de intercambios, de diferencias y aproximaciones y sobre todo, de coexistencia de historias. A partir de la relación que se puede establecer entre estas discontinuidades y el (des)montaje de los espacios y la memoria, se abre el territorio de la poesía: "una apariencia de continuidad /Quebrado, cosido/ el verso elide en su secuencia, / su ajuste su descontrol/ en un trazo de palabras, /agarres/ para boyar sobre napas/ escurridizas" (239). El quehacer simultáneo de la voz enunciativa es hacer memoria y poesía como ejercicio transgresor que busca desorientar la sucesión simbólica y así traducir la memoria poética en una interrogante crucial sobre las ordenaciones de lo evidente y lo decible.

De esta manera, Puentes poetiza la tensión entre el desvío y el mandato de la memoria, asumiendo una voz crítica que contrapone una "dislocación" a la búsqueda de fundamentos en/de la experiencia y con lo que, además, identifica los tránsitos migratorios de la sujeto. La palabra poética forma parte esencial de la deriva o alteración que acontece en los puentes, siendo ella misma un puente, una "elipsis" que dice en "diferido", representando el "degaste / sobre el hierro forjado / 
de los puentes" (252). La poesía es el "agarre" de la sujeto a su propia historia, con ella la enunciación puede "quebrar la escarcha / cruzar al otro margen" (252) ${ }^{14}$. Es así como el tiempo y el espacio de la memoria y de la poesía en Genovese coinciden, puesto que la orientación temporal y espacial que vive la sujeto impulsa la orientación de su palabra poética. La hablante elabora su propio lugar en referencia a la experiencia ética que ha decidido sea su esfera de creación y que "la cámara no alcanza", porque evidentemente "queda fuera de[1] foco" (248) de las "fotografías: /férreos espacios familiares" (247).

Lo dicho hasta aquí supone una política de la mirada en relación con la experiencia temporal y espacial de la "realidad" que, al apartarse de la trayectoria establecida, visualiza y construye una ruta diferida hacia lo "otro". De esta forma, el enfoque visual de la sujeto plantea dialogías éticas y afectivas, no tan solo con la emancipación de aquellos imaginarios, experiencias y perspectivas que la "principalidad" histórica ha relegado al margen, sino también con el proceso de creación poética.

En uno de sus ensayos sobre la poesía trasandina, Alicia Genovese (2015) propone la noción de "poeta migrante" que hace alusión al poeta que se desplaza, que va y que retorna con su lenguaje, "al mismo tiempo que establece en él su casa y marca de pertenencia” (129). Para Genovese la poesía llega hasta lugares descivilizados — desviados-donde habitan las fronteras del grito, del gemido, de la necesidad, del deseo y del miedo; convirtiéndose en un inclemente territorio de la experiencia sensible (130). En consecuencia, “[e]l poeta migrante - dice la autora- es aquel que necesita exiliarse, establecer o construir un tiempo fuera del tiempo de sucesión inapresable, pero que mantiene lazos materiales con ese tiempo." (130). En esta perspectiva, pensamos que el trabajo poético que hay en Puentes apunta en esta dirección y, por otro lado, consideramos que la correspondencia que existe entre la voz enunciativa y su necesario hacer poético tiene dos niveles. El primero de ellos se relaciona con lo que ya hemos mencionado, esto es, la hablante lírica es efectivamente una sujeto de migrancias que potencia la relación con y en otros lugares y tiempos del lenguaje, entendiendo este último como acto comunicativo de posibilidades artísticas y en el cual acontecen transferencias, variaciones y emancipaciones de distinto tipo. Sin embargo, el poemario igualmente señala que esta dislocación de la experiencia creativa (vital)

$14 \quad$ La cursiva es del original. 
no puede materialmente disociarse del plano histórico convencional y del tiempo oficial. Dicho de otro modo, mediante la metáfora del desvío en el poemario, se narra la historia de una sujeto que transita su experiencia biográfica a partir de una memoria poética localizada y, a la vez, articulada a violentos acontecimientos históricos en Argentina. Ejemplo de esto es el golpe de Estado en contra de Perón en 1955, el movimiento estudiantil a fines de los sesenta y comienzo de los setenta y la última dictadura militar (1976-1983):

Desaparecido, chupado
el nudo se abre
con un legajo oculto, pruebas
de ADN, indisoluble filiación
en ácido de los cuerpos
y la historia fragmentada
[...]. Imaginario
que vuelve a contar
a alterar la inscripción
de la catástrofe $(236)^{15}$

La entrada de la historia al poemario, además de reforzar la cronotopía de las imágenes, potencia la yuxtaposición que existe, por ejemplo, entre estos "primeros" planos de violencia y las focalizaciones metafóricas "descentradas" que "construyen puentes/ hacia dentro, / hacia el agua sumergida" (241). Esta bisagra que, simultáneamente es articulación y descalce, es el segundo nivel que nos planteamos para la acción poética que ejerce la sujeto lírica. En ella se manifiesta un orden y una variación que teje diversas posibilidades de la intimidad de la memoria, operando siempre como una interrogante crítica de la imagen poética: "de la ira y el sueño se vuelve/ del suelo minado/ y el ansia, empieza/ un puente." (253). Es así como el quehacer de la sujeto poética, la escenificación de su memoria, su habitar lúcido y desvariado en los puentes tienen que

\footnotetext{
15 El fragmento citado alude a que durante la última dictadura militar en Argentina cientos de niños y niñas fueron secuestrados junto a sus padres y madres, otras nacieron mientras sus madres embarazadas estaban prisioneras. Algunos de estos niños fueron repartidos entre familias de militares, otros abandonados como NN y otros vendidos. En 1995 se funda la agrupación de derechos humanos H.I.J.O.S (Hijos e Hijas por Identidad y Justicia contra el Olvido y el Silencio), la que está integrada por hijos e hijas de presos políticos, exiliados, desparecidos y asesinados en esta dictadura. Su objetivo principal es luchar contra la impunidad, la reconstrucción de la verdad histórica, la restitución de la identidad de los niños y niñas secuestrados/as y apropiados/as y la cárcel efectiva para los responsables de crímenes de lesa humanidad durante la última dictadura.
} 
ver con la dislocación hacia el encuentro con lo "otro" interno y externo en el tiempo y en el espacio. Dislocación que se inicia, como dijimos, en el momento en el que la sujeto decide desalinearse del camino de su madre para hallar sus propios puentes de salida, tránsito, retorno y desvío hasta el encuentro con su hija y la poesía. De aquí en adelante y dentro de un manejo lentificado del tiempo - a contrapelo del tiempo tecnológico y mercantilizado-, se suceden en diferentes sentidos de trayecto distintos distanciamientos, aproximaciones y alteraciones de los planos "centrales" en las imágenes de la memoria. En efecto, toda huella que rememora y visualiza la sujeto es parte de un acto creativo; sin ello no le es posible apropiarse de sus propios puentes que articulen el movimiento dialógico imprescindible en una existencia poética.

La figura del puente en los poemas de Genovese se construye como un cronotopo de potente visualidad poética y como una especie de foco nodal de la memoria que configura los sentidos y los afectos que sostienen la nomadía de la enunciación. Los cronotopos hacen alusión a las formas en que el tiempo entra o se hace visible en el espacio, principalmente a los modos en que un tiempo es elaborado en el espacio que se representa en una obra de arte, específicamente, en la narración literaria. Pues bien, la cronotopía en los poemas de Genovese se evidencia en el ensamble poético entre el tiempo de la memoria (des)focalizada y el espacio heterogéneo del puente y que, a la par, como resultado del intercambio semántico que existe entre ambas dimensiones de la experiencia, una es representación del otro y viceversa. Asimismo, el puente se constituye como un "cronotopo de la intimidad" en cuanto "pone en forma $-\mathrm{y}$, por ende, en sentido- la propia experiencia” (Arfuch, "Cronotopías de la intimidad" 242). Todavía más, la cronotopía del puente le entrega a la memoria una atmósfera diferenciada que le permite desenvolver la mirada poética de las imágenes, facilitándole un acercamiento al foco íntimo de la experiencia temporal y que ahonda en la visualidad afectiva del lenguaje poético.

Nos interesa en esta perspectiva, la concepción de una constitución de sujeto dentro de una inevitable interacción del otro/a o de lo otro en mí. Clave es, a nuestro juicio, que esta relación de "interdependencia" en la experiencia, es la base de una intimidad que desmonta cualquier identidad predeterminada en un "para sí" del sujeto, manifestando una alteridad política y ética que se filtra del repliegue opositivo mismo/ otro. En este sentido, es que la alteridad toma el ritmo migrante que 
le proporciona Alicia Genovese y que según Rosi Braidotti (2009), se trataría de una política nómada que abre significativas posibilidades para intervenir en un espacio mediado por las continuidades discursivas de lo homogéneo: "Un puente es un salto,/ una elipsis/ que dice en diferido/ su argumento/ una apariencia de continuidad" (239). Más aún, para Genovese (2015) el “yo" poético tiene que ver con un "arrastre subjetivo" (213) que interpretamos como el tránsito hacia una inflexión que abre otros caminos y otros pasajes de interacción con la experiencia y donde el "alter" se disemina en esos otros lugares de la intimidad y que son poetizados en la dimensión más visual del lenguaje. Ejemplificamos con el siguiente fragmento, el que es continuación de otro citado más arriba y que se refiere a la apropiación de niños y niñas que realizó en la última dictadura en Argentina:

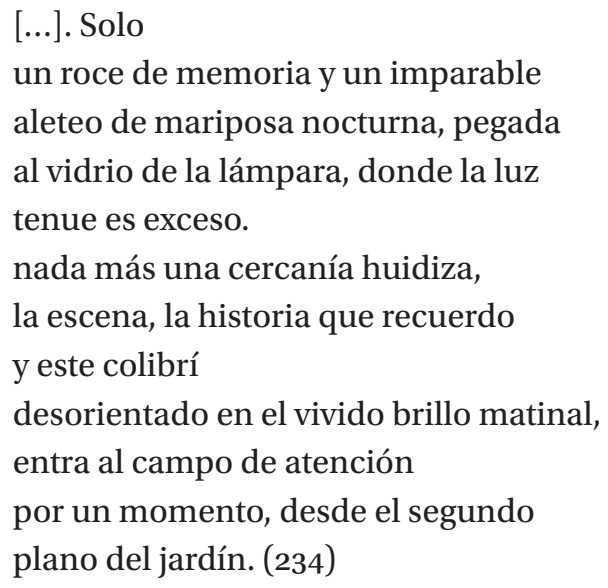

Este espacio fronterizo que revela el movimiento de las imágenes de la memoria, primero, con la introducción de la violencia histórica en el poema y luego, con el deslizamiento hacia la mirada subjetiva de la enunciación, se construye en un lugar-tiempo en el que el encuentro y desencuentro con la alteridad significan, en cualquier caso, reconocerla y explorarla. A partir de esta óptica, la enunciación interroga la problemática del lugar de la sujeto lírica con su "historia" al interior de "la Historia" a partir de la poesía misma: recordemos que el puente es un cronotopo metapoético. Así, este lugar enunciativo se convierte en un potencial espacio de emancipación y donde la sujeto establece su principal referente de identificación (Salomone, "Escritura, imagen y política..." 144). En este sentido, Stavrides (2016) afirma que "las espacialidades de emancipación" funcionan como territorios de alteridad 
y margen dentro de una ordenación espacial urbana determinada y para poder construir un puente que permita el tránsito y el intercambio con y entre estos espacios de diferenciación, es necesaria la distancia. Es más, para el autor, estas espacialidades de umbral, estarían relacionadas con procesos de identidad emancipatoria en cuanto se construyen como heterotopías: "Más allá y contra la ciudad de enclaves, los espacios heterotópicos marcan los umbrales en el espacio y en el tiempo en el que se cuestiona el orden y el control dominantes". (27-28). Asimismo, Stavrides (2007) nos señala que "[s]i la vida cotidiana no es solo un lugar de reproducción social, sino que además contiene prácticas de 'auto diferenciación' o de resistencia personal o colectiva, entonces se pueden encontrar espacialidades moleculares de resistencia de la 'otredad' dispersadas por la ciudad" (119).

De esta forma, el espacio-temporal en el poemario se construye como una cronotopía heterotópica y donde la experiencia fronteriza de la sujeto y su desplazamiento político en lo cotidiano de la memoria, es vivido como alteridad. Por otra parte, a partir de la intimidad, las fronteras se complejizan aún más, puesto que el umbral no solo se teje en este sentido, sino que interactúa con los cruces entre la memoria, la imagen, la voz y el lenguaje. Nos referimos aquí a que la poetización de la experiencia migrante de la enunciación, situada en la mirada, se hace cardinal, puesto que aquello que la imagen pone en lenguaje o viceversa, es donde la poesía desenvuelve su apuesta mayor. Al respecto, Alicia Salomone, siguiendo lo que propone Enrique Foffani para Puentes, afirma que la composición de la imagen —especialmente fotográfica de los poemas de Genovese-, "permite apuntar a la dimensión óptica de la poesía y a su capacidad para multiplicar la visión sobre una superficie siempre evanescente, a la que, sin embargo, se procura capturar en un instante" ("Puentes de Alicia Genovese..." 33).

El libro de Alicia Genovese supone el adentro y el afuera de la imagen o el interior y exterior de la palabra poética, entre lo que está y lo que se halla ausente o fuera de escena para atravesar el coto de la representación, es decir, el límite del orden simbólico. Para esto abre un cronotopo de pasaje que estimula el sentido de cruce hacia otros bordes y donde se produce la variación de la memoria y del lenguaje, por ende, de la experiencia. En este punto puede ser útil la figura deleuziana del "pliegue" (Deleuze, 1989) para enfocar la imagen del puente, cuyo doblez involucra uno y otro lado, evitando la construcción estable y 
continua de las posiciones y los espacios, además de llevar consigo un flujo entre la interioridad y la exterioridad, entre la autonomía del interior y las restricciones y condiciones del exterior. Sin embargo, nos parece que en libro de Alicia Genovese no todo es discontinuidad, puesto que no solo hay que entender el puente como una figura metafórica, sino que también es necesario percibirlo en su relación con la enunciación. Es en ella que cobra su sentido poético de transgresión y contravención a la lógica de lo esperable. Por lo tanto, en la reiteración del acto poético se despliega una sutil y dinámica continuidad que alude, sin duda, a la energía del deseo de manifestar "otra” cosa. Esta función de "otredad" de la poesía en la poesía que emerge en Puentes, se compromete como un sostenimiento de resistencia y emancipación respecto de lo prefigurado.

\section{Notas finales}

Sin duda que Calamina y Puentes son poemarios que se diferencian en sus facturas artísticas, especialmente en la posición "geopoética" que viven las hablantes y en el formato y extensión de los poemas. Para la primera, si bien el nomadismo es imprescindible, también lo es la compleja relación entre el yo, el lenguaje y el espacio. Por lo mismo, interpretamos que tanto en González (2014) como en Genovese(2018) estas dimensiones del mapa poético se cumplen, incluyendo aquí, que ambas sujetos poéticas experimentan una especie de exilio voluntario. Sin embargo, las enunciaciones se sitúan en distintas focalizaciones de la marginalidad y con objetivos que también son distintos. En Calamina, la hablante va revelando su propio itinerario de muerte, vale decir, las condiciones del "patio trasero" en el que desenvuelve su trayecto y en el cual anida la soledad y la pobreza como residuos virales del sistema de mercado. Por su parte, en Puentes, la voz enunciativa se desliza hacia la palabra poética como intervalo de resistencia o sobrevivencia, tratándose de un territorio vital que va a contrapelo del territorio simbólico. En relación con la extensión de los poemas, el libro de Genovese es un solo poema espaciado, no tiene ningún título ni apartado; en cambio, el poemario de González si bien es o podría configurarse, igualmente, como un solo poema - ya que se mantiene un hilo conductor en la narración poética-, está dividido en partes y títulos que enfatizan ciertos recortes en la precariedad de la historia poética. 
Asumimos que estas diferenciaciones de los textos constituyen un valor artístico para nuestra lectura, puesto que a través de ellas se pueden reconocer o resituar heterogeneidades poéticas que apuntan con diferentes estrategias poéticas, a la descompresión de los significados. Allí es donde encontramos intercambios de sentido artístico compartidos o próximos, entre ambas facturas poéticas. Fundamental, en este sentido, son las representaciones de la intimidad, las que poseen un gran despliegue visual de la palabra y bordean cierta precisión metafórica de la imagen, importunando, por una parte, la percepción del espacio cotidiano domesticado y, por otro, las temporalidades dominantes de la memoria. De esta manera, las voces poéticas van duplicando, triplicando o muchas veces multiplicando su territorio de enunciación, aunque siempre sea el mismo: la precariedad, el desamparo y la errancia en Calamina y la memoria, la nomadía y la poesía en Puentes.

El desenvolvimiento de una poética más visual, creemos, se logra, entre otras sutilezas artísticas y políticas, a partir del reconocimiento del doble imaginario simbólico que tiene la mirada y la poesía. El énfasis visual que posee el lenguaje poético —en relación con lo que no es visto, no se ha podido ver, se ha prohibido ver o no se ha querido ver-, le asigna a la mirada "trasera" de (y sobre) la experiencia, un lugar central. En ambos poemarios, esta mirada provoca un "efecto visual" de la escritura que traspasa las fronteras entre la imagen, el lugar y la intimidad. A través de la mirada "migrante" que asumen las sujetos poéticas, los lugares y la experiencia se integran para desmontar la preexistencia de patrimonios de permanencia y estabilidad en los espacios oficiales.

En Calamina la imagen de los lugares - la bahía, la habitación, la calle, la ventana, la estación de buses, el hospital, etc.-, a la vez que aparecen con alguna claridad "realista" que los intensifica, se descomponen por la intervención o mediación de la voz y el cuerpo de la sujeto. Estos últimos — voz y cuerpo-, son parte fundamental de la escena vista, porque actúan como señas veladas y degradadas dentro del marco oficial de la ciudad-puerto y de la mercantilización de los afectos. Se destaca el juego entre lo opaco-nocturno, la claridad de las imágenes y la escritura, ya que a través de él se presiente y se observa una violencia acumulada tanto en los objetos y en los lugares, como en el cuerpo. De aquí la importancia del oficio de la escritura para la hablante, porque la poesía funciona como una estrategia de 
rehabilitación o sobrevivencia que se desplaza junto a la mirada. Ejemplo de esto es la articulación entre la imagen visual de la calamina en la portada y contraportada del libro y el nombre del poemario. Esta es la primera entrada poética de lo visual en la escritura, la que se sostiene, a través de diversos enfoques y movimientos de la mirada del lenguaje, durante toda la lectura del poemario.

Por otra parte, el texto de Alicia Genovese abre la figura de los puentes que, proyectados de manera oblicua, cruzan a otros territorios de la experiencia. De aquí que el puente sea un cronotopo de desvío o variación, no para huir o evadir, sino para acceder a la alteridad y, de esta forma, promover una alteración en la normalización de la experiencia histórica y familiar. En los poemas, de hecho, los primeros planos de las jerarquías simbólicas - las estructuras de fierro de los puentes, la línea férrea que ocupa el lugar de un río o las fotografías familiares-, son atravesados por la poética de una mirada que actúa como política íntima de la memoria. Así, la cronotopía de la alteridad perturba el devenir oficial, desarreglando sus categorías.

La visualidad que adquiere la huella de los desvíos en las imágenes del poemario, potencia la fuerza migratoria de la mirada en la memoria. Con esto se resalta la irregularidad de los ralentizados movimientos de ida, de vuelta y dislocación que realiza la voz poética entre su interioridad y su exterioridad. Todo, como un movimiento pausado de la palabra-imagen que no deja de alterar las líneas de tensión entre ella y el significado establecido para reescribir las cartografías de puentes reales, esto es, se poetiza la experiencia íntima en/de la memoria.

Tanto González como Genovese recurren al efecto-imagen que, sabemos, tiene el lenguaje poético, pero que en estos poemas se acentúa para capturar breves deslizamientos lugarizados de la experiencia. Corresponden a representaciones políticas del margen o de fronteras disruptivas con las narrativas de la totalidad y a partir de las cuales se manifiesta la alteridad y con ello, por supuesto, cobra vitalidad la relación yo-otro y a la inversa. En ambos textos se complejiza la existencia del yo, porque al abrir desvíos hacia un "alter" ya sea espacial, temporal, identitario, material, simbólico, interior o ajeno se introduce la posibilidad política y ética de un "nosotros" de descalce, lo que aporta significación a las relaciones humanas. La interrogante por el vínculo afectivo es necesaria en ambos poemarios, solo que en uno es un viaje sin retorno al exilio y al autoexilio (Calamina) y en el otro, es la migrancia por 
la intimidad de la memoria para lograr construir el vital vínculo amoroso de la sobrevivencia, el desvío-encuentro de la sujeto con su hija y con la poesía.

Los paralelismos que podemos hallar entre ambos libros además de los mencionados podrían, eventualmente, ampliarse para un trabajo posterior. Entre ellos se encuentran la relación exilio-autoexilio, el viaje, el conflicto de la felicidad y los afectos, la resistencia a las "postales congeladas" (Genovese, Puentes 227) y la construcción de fronteras como lugares mínimos y complejos. Todas ellas nos parecen que son potenciales interrogantes no solo en la escritura de Gladys González y Alicia Genovese, sino también en la poetización de las dislocaciones en el campo artístico de mujeres en una relación "sur-sur" y donde deben relevarse también, otras poéticas actuales fundamentales como, por ejemplo, la de mujeres mapuche que se produce a ambos lados de la cordillera.

\section{Referencias bibliográficas}

Alberdi, Begoña. "Escribir la imagen: la literatura a través de la écfrasis". Literatura y Lingüística, no. 33, 2016, pp. 17-38.

Amaro, Lorena. “La poesía escópica de Gladys González ('o el patio trasero del lado salvaje')”. Letras en Línea, 2018, s.p. Recuperado de http://www.letrasenlinea.cl/

Arfuch, Leonor. Memoria y autobiografía. Exploraciones en los límites. Buenos Aires, Fondo de Cultura Económica, 2013.

“Cronotopías de la intimidad". Pensar este tiempo: espacios, afectos y pertenencias. Comp. Leonor Arfuch. Buenos Aires, Fondo de Cultura Económica, 2005, pp. 237-290.

Bajtín, Mijail. Hacia una filosofía del acto ético. Barcelona, Anthropos, 1997.

Teoría y estética de la novela. Madrid, Taurus, 1989.

Braidotti, Rosi. Transposiciones. Sobre la ética nómada. Barcelona, Gedisa, 2009.

Brito, Eugenia. "La poética de Calamina de Gladys González”. Letras. mysite, 2014. s.p. Web. Recuperado de http://letras.mysite. com/ggon150414.html 
Deleuze, Gilles. El pliegue: Leibniz y el Barroco. Barcelona, Ediciones Paidós Ibérica, 1989.

Genovese, Alicia. La línea del desierto. Poesía reunida. Buenos Aires, Gog \& Magog, 2018.

"Irse lejos para encontrar lo propio. Migración y pertenencia en la poesía argentina contemporánea". Memoria e imaginación poética en el Cono Sur (1960-2010). Ed. Alicia Salomone. Buenos Aires, Corregidor, 2015, pp. 129-144.

Leer poesía. Lo leve, lo grave, lo opaco. Buenos Aires, Fondo de Cultura Económica, 2011.

"Marcas de graffiti en los suburbios: poesía argentina de la posdictadura". Revista Iberoamericana, vol. 69, n² 202, 2003, pp. 199-214.

González, Gladys. Calamina. Santiago de Chile, La Calabaza del Diablo, 2014.

González, Gladys. "Entrevista a Gladys González: Abrir espacios para todos”. Entrevista Juan Francisco Urzúa. El Ciudadano, 2018, s.p. Web. Recuperado de https://www.elciudadano. $\mathrm{cl} /$ artecultura/artes/letras/entrevista-a-gladysgonzalez-abrir-espacios-para-todos/\#ixzz5VAieo4LH

Lyotard, Jean-Francois. Discurso, figura. Barcelona, Gustavo Gili, 1979.

Menard, Andrés. "Sobre las ruinas de un canto (el ruido, la supervivencia y el lenguaje de las cosas)”. La instancia de la música. Eds. Olga Grau y otros. Santiago de Chile, UMCE/Universidad de Chile, 2014, pp. 223-231.

Mitchell, W. J. T. Teoría de la imagen. Ensayos sobre representación verbal y visual. Madrid, Akal, 2009.

Perec, Georges. Lo infraordinario. Madrid, Impedimenta, 2007.

Puppo, María Lucía. Entre el vértigo y la ruina. Poesía contemporánea y experiencia urbana. Buenos Aires, Editorial Biblos, 2013.

Rancière, Jacques. El destino de las imágenes. Buenos Aires, Prometeo Libros, 2011.

Ricoeur, Paul. La metáfora viva. Madrid, Editorial Trotta-Ediciones Cristiandad, 2001. 
Salomone, Alicia. "Escritura, imagen y política en dos poetas argentinas: Alfonsina Storni y Alicia Genovese”. Atenea, no. 499, 2009, pp. 135-148.

"Puentes de Alicia Genovese: poesía y memoria en la Argentina de la posdictadura". Boca de Sapo, no. 4, año 10, 2009, pp. 33-37. Recuperado de http://studylib.es/doc/8238154/ boca-de-sapo-n-\%C2\%BA04.

Sepúlveda, Magda. Ciudad quiltra. Poesía chilena (1973-2013). Santiago de Chile, Editorial Cuarto Propio, 2010.

Stavrides, Stavros. Hacia la ciudad de umbrales. Madrid, Ediciones Akal, 2016.

"Espacialidades de emancipación y la 'ciudad de umbrales'”. Bajo el Volcán, vol. 7, no. 11, 2007, pp. 117-124. 